\title{
Rates of asthma exacerbations and mortality and associated factors in Uganda: a 2-year prospective cohort study
}

\author{
Bruce J Kirenga, ${ }^{1,2}$ Corina de Jong, ${ }^{3,4}$ Levicatus Mugenyi, ${ }^{1,5}$ Winceslaus Katagira, ${ }^{2}$ \\ Abdallah Muhofa, ${ }^{2}$ Moses R Kamya, ${ }_{1}$ H Marike Boezen, ${ }^{6}$ Thys van der Molen ${ }^{3,4}$
}

\begin{abstract}
- Additional material is published online only. To view please visit the journal online (http://dx.doi.org/10.1136/ thoraxjnl-2017-211157).

${ }^{1}$ Makerere University Lung Institute, Makerere University College of Health Sciences, Kampala, Uganda

${ }^{2}$ Department of Medicine, Makerere University College of Health Sciences, Kampala, Uganda

${ }^{3}$ GRIAC-Primary Care,

Department of General Practice and Elderly Care, University of Groningen, University Medical Center Groningen (UMCG),

Groningen, The Netherlands

${ }^{4}$ Groningen Research Institute for Asthma and COPD (GRIAC) University of Groningen, University Medical Center Groningen (UMCG), Groningen, The Netherlands

${ }^{5}$ Center for Statistics, Interuniversity Institute for Biostatistics, and Statistical Bioinformatics, Hasselt University (UHasselt), Groningen, The Netherlands ${ }^{6}$ Department of Epidemiology, University of Groningen, Groningen, The Netherlands
\end{abstract}

\section{Correspondence to}

Dr Bruce J Kirenga, Makerere University Lung Institute, Mulago Hospital, Kampala 7072, Uganda; brucekirenga@yahoo.co.uk

Received 16 October 2017 Revised 6 April 2018 Accepted 16 April 2018 Published Online First 11 May 2018 thoraxjnl-2018-211718

\section{Check for updates}

To cite: Kirenga BJ, de Jong $C$, Mugenyi L, et al. Thorax 2018:73:983-985.

\section{ABSTRACT}

Data on asthma treatment outcomes in Africa are limited. 449 patients with asthma (age 5-93 years) in Uganda were followed up for 2 years to determine rates of exacerbations and mortality and associated factors. During follow-up the median number of exacerbations per patient was 1 (IQR 0-5) and 17 patients died (3.7\%, 27.3 deaths per 1000 person years). Considering only the first year of follow-up, $59.6 \%$ of the patients experienced at least one exacerbation, $32.4 \%$ experienced three or more exacerbations. A multivariable model showed that the likelihood of experiencing at least one exacerbation in the first year of follow-up was lower with better baseline asthma control (higher asthma control test (ACT) score), with OR 0.87 (95\% $\mathrm{Cl}: 0.82$ to $0.93, \mathrm{P}=0.000$ ), and was higher with more exacerbations in the year prior to enrolment (OR for log number of exacerbations $1.28,95 \% \mathrm{Cl}: 1.04$ to 1.57 , $\mathrm{P}=0.018)$. Better asthma control (OR 0.93, 95\% Cl: 0.88 to $0.99, P=0.021)$ and number of baseline exacerbations (OR $1.35,95 \% \mathrm{Cl}: 1.11$ to $1.66, \mathrm{P}=0.005$ ) were also the only factors that were independently associated with experiencing three or more exacerbations during the first year of follow-up. The only factor found to be associated with all-cause mortality was $\mathrm{FEV}_{1}$, with higher recent $F E V$, associated with lower all-cause mortality (OR $0.30,95 \% \mathrm{Cl}: 0.14$ to $0.65 ; P=0.002$ ). Rates of asthma exacerbations and mortality are high in Uganda and are associated with poor asthma control. Health systems should be strengthened to care for asthma patients.

\section{BACKGROUND}

Asthma exacerbations and mortality are the worst asthma treatment outcomes. ${ }^{1}$ Asthma exacerbations are responsible for most asthma morbidity, healthcare utilisation, poor quality of life and precede most asthma deaths. ${ }^{2}$ Some patients experience frequent asthma exacerbations (defined usually as experiencing at least three exacerbations in a year). These patients have been described as having an exacerbation-prone asthma phenotype in some literature ${ }^{3}$ and are at the greatest risk of adverse asthma outcomes, including death. The risk factors for exacerbations include low use of inhaled corticosteroids, allergic rhinitis, seasonal changes, gastro-oesophageal disease, psychosocial factors, recurrent chest infections, aspirin intolerance, cigarette smoking, non-adherence to medications, obesity and higher number of exacerbations in the past year. $^{3}$
Globally, asthma mortality is estimated at $0.19 / 100000$ population. ${ }^{4}$ According to a recent analysis of asthma mortality in 46 countries, asthma mortality rates were observed to be decreasing in the 1990s through the 2000s but have recently stagnated. ${ }^{4}$ Asthma mortality rate was 0.44 deaths per 100000 people in 1993 and reduced to $0 \cdot 19$ deaths per 100000 people in 2006 but no significant change was observed between 2006 and 2012. ${ }^{4}$ There are significant disparities in asthma mortality between countries, with low and middle income countries having the highest number of asthma deaths. Risk factors for asthma mortality include older age, gender, African race, low use of inhaled corticosteroids (ICS), inappropriate use of long-acting $\beta$ agonists (LABAs), fixed airway obstruction (lack of reversibility), previous exacerbation, low $\mathrm{FEV}_{1}$ and psychological and psychosocial factors. ${ }^{5}$

Data on asthma exacerbations and mortality and their predictors in Africa are severely limited. We therefore set up this prospective cohort study called the Uganda Registry for Asthma and Chronic Obstructive Pulmonary Disease (URAC) to document the rates of asthma exacerbations and mortality, and their predictors in Uganda.

\section{METHODS}

URAC is conducted in the chest clinics of six tertiary hospitals in Uganda, namely Mulago Hospital, Mbarara Hospital, Mbale Hospital, Hoima Hospital, Arua Hospital and Gulu Hospital. For the current analysis, only patients enrolled at Mulago Hospital are included. The Mulago Hospital Research and Ethics Committee and the Uganda National Council for Science and Technology approved this study. All patients with asthma who were 5 years and older for whom consent was provided were enrolled and followed up every 6 months for 2 years. Using a standardised clinical record form (CRF), data on patients' socio-demographics, clinical and lung function were collected. Asthma control was measured at each visit using the Asthma Control Test (ACT). All patients underwent spirometry according to American Thoracic Society/ European Respiratory Society (ATS/ERS) guidelines using a Pneumotrac spirometer with Spirotrac V software (Vitalograph Ltd, Buckingham, UK). Predicted parameters were based on NHANES III models for African Americans. Asthma medication prescriptions were based on GINA guidelines.

Median number of exacerbations per patient over the entire 2-year follow-up period was 
calculated. The proportions of patients experiencing at least one exacerbation and at least three exacerbations during the first year of follow-up were calculated. First data on exacerbations were considered to avoid recall bias and because of the high attrition rate (32.5\%) and the fact that less than 50\% of the cohort could be followed up by this time. Exacerbations were defined according to the ATS/ERS definitions. Death was by postmortem reports and verbal autopsy, and all-cause mortality was considered. Incidence of death was calculated as the number of deaths during the total follow-up period divided by the total follow-up time in years. Factors associated with all-cause mortality were analysed using the Cox proportional hazards model with age at death used as the survival time variable while factors associated with exacerbations (at least one and at least three exacerbations per year were determined using logistic regression.

\section{RESULTS}

From 13 August 2013 to 24 April 2016, 449 patients with asthma $(28.3 \%$ male, median age 33 years (IQR 20-48)) were enrolled into the URAC Registry at Mulago Hospital. Patients' socio-demographic characteristics are presented in table 1 . At baseline, $32.2 \%$ of the patients had controlled asthma and $33.0 \%$ had evidence of airflow obstruction on spirometry (ie, had $\mathrm{FEV}_{1} / \mathrm{FVC}$ ratio $<0.70$ ). Smoking was reported by $12 \%$ of the patients, HIV by $6 \%$, history of tuberculosis treatment by $6.2 \%$, nasal congestion by $88.2 \%$ and heartburn by $60.6 \%$. A total of $147(32.7 \%)$ patients were on either ICS alone or ICS/ LABA at baseline.

\section{Exacerbations}

The proportion of patients who experienced at least one exacerbation during the first year was $59.6 \%$ (268) while $32.4 \%$ (133) experienced at least three exacerbations in the first year. At the bivariate level, experiencing at least one exacerbation in the first year was associated with respiratory rate (OR 2.58, 95\% CI: 1.01 to $6.57, \mathrm{P}=0.047$ ), having used ICS prior to the clinic visit (OR 2.93, 95\% CI:1.56 to $5.48, \mathrm{P}=0.001$ ), number of baseline exacerbations (OR 1.47, 95\% CI: 1.21 to 1.79, $\mathrm{P} \leq 0.001)$, asthma control test (ACT) scores (OR 0.89, 95\% CI: 0.85 to $0.94, \mathrm{P} \leq 0.001)$ and $\mathrm{FEV}_{1}(\mathrm{OR} 0.56,95 \% \mathrm{CI}: 0.35$ to $0.89, \mathrm{P}=0.014)$; while experiencing three or more exacerbations was associated with age (OR 1.71, 95\% CI: 1.17 to 2.50 , $\mathrm{P}=0.006$ ), number of baseline exacerbations (OR 1.48, 95\% CI: 1.22 to $1.79, \mathrm{P}<0.001)$, having used ICS prior to the clinic visit (OR 1.96, 95\% CI: 1.14 to $3.35, \mathrm{P}=0.014$ ), respiratory rate (OR 2.14, 95\% CI: 1.04 to $4.40, \mathrm{P}=0.039)$, ACT scores (OR $0.84,95 \%$ CI: $0.79-0.89, \mathrm{P}<0.001$ ), $\mathrm{FEV}_{1}$ (OR $0.64,95 \%$ CI: 0.41 to $0.99, \mathrm{P}=0.044$ ), $\mathrm{FEV}_{1} / \mathrm{FVC}$ ratio (OR $0.11,95 \%$ CI: 0.03 to $0.46, \mathrm{P}=0.011$ ) and exposure to biomass smoke exposure (OR $0.54,95 \%$ CI: 0.30 to $0.99, \mathrm{P}=0.048$ ).

At multivariate analysis the only factors independently associated with experiencing at least one exacerbation in the first year of follow-up were ACT score (OR 0.87, 95\% CI: 0.82 to $0.93, \mathrm{P}=0.000$ ) and number of baseline exacerbations (OR $1.28,95 \% \mathrm{CI}: 1.04$ to $1.57, \mathrm{P}=0.018)$. ACT score (OR $0.93,95 \%$ CI: 0.88 to $0.99, \mathrm{P}=0.021$ ) and number of baseline exacerbations (OR 1.35, 95\% CI: 1.11 to 1.66, $\mathrm{P}=0.005)$ were also the only factors independently associated with experiencing three or more exacerbations during the first year of follow-up.
Table 1 Baseline patients' characteristics

\begin{tabular}{|c|c|c|}
\hline Characteristic & Number & Percentage \\
\hline Male gender & 127 & 28.3 \\
\hline \multicolumn{3}{|l|}{ Age groups } \\
\hline$<15$ & 54 & 12.0 \\
\hline $15-24$ & 87 & 19.4 \\
\hline $25-34$ & 91 & 20.3 \\
\hline $35-44$ & 83 & 18.5 \\
\hline $45-54$ & 60 & 13.4 \\
\hline $55-64$ & 38 & 8.5 \\
\hline $65+$ & 36 & 8.0 \\
\hline \multicolumn{3}{|l|}{ Respiratory symptoms } \\
\hline Cough & 379 & 84.4 \\
\hline Sputum & 214 & 47.7 \\
\hline Wheezing & 434 & 96.7 \\
\hline Shortness of breath & 436 & 97.0 \\
\hline \multicolumn{3}{|l|}{ Lung function abnormalities } \\
\hline $\mathrm{FEV}_{1} / \mathrm{FVC}$ ratio $<0.70$ & 148 & 33.0 \\
\hline $\mathrm{FEV}_{1} \geq 80 \%$ predicted & 211 & 47.0 \\
\hline FEV $, \%, 50-79 \%$ predicted & 163 & 36.3 \\
\hline $\mathrm{FEV}_{1} \%, 30-49 \%$ predicted & 58 & 12.9 \\
\hline $\mathrm{FEV}_{1} \%,<30 \%$ predicted & 17 & 3.8 \\
\hline \multicolumn{3}{|l|}{ Asthma control } \\
\hline Uncontrolled, $\mathrm{ACT}<15$ & 126 & 28.1 \\
\hline Partially controlled, $15 \leq \mathrm{ACT} \leq 19$ & 174 & 38.8 \\
\hline Controlled, ACT>19 & 149 & 33.2 \\
\hline \multicolumn{3}{|l|}{ Medications } \\
\hline Salbutamol inhaler & 318 & 70.8 \\
\hline Inhaled corticosteroids & 83 & 18.5 \\
\hline Combination inhalers (steroid, LABA) & 64 & 14.3 \\
\hline Leukotriene modifiers & 66 & 14.7 \\
\hline \multicolumn{3}{|l|}{ Risk factors and comorbid conditions } \\
\hline History of smoking & 54 & 12.0 \\
\hline Exposure to bio-mass* & 390 & 86.9 \\
\hline Ever been treated for TB & 28 & 6.2 \\
\hline HIV positive & 27 & 6.0 \\
\hline Nasal congestion or rhinorrhea & 396 & 88.2 \\
\hline Heart burn/acid irritation & 272 & 60.6 \\
\hline
\end{tabular}

*Including use of wood, charcoal and kerosene for cooking or lighting. ACT, Asthma Control Test; LABA, long-acting $\beta$ agonist; TB, tuberculosis.

\section{Mortality}

Overall 17 patients died (3.7\%), 11 (64.7\%) from circumstances judged to be asthma related (online supplementary table 2). The incidence of all-cause mortality was 27.3 per 1000 -person years, male vs female, 34.2 vs 24.6 , incidence death rate ratio $1.39(0.42$ 4.09) and increased with age (online supplementary table 1). At bivariate analysis, all-cause mortality was associated with $\mathrm{FEV}_{1}$ and FVC (adjusted hazard ratio $0.30,0.14-0.65, \mathrm{P}=0.002$; and 0.28 , $0.12-0.68, \mathrm{P}=0.005)$ respectively while history of tuberculosis treatment (adjusted HR 3.10, 1.00-9.65, $\mathrm{P}=0.051$ ) and use of herbs (adjusted HR 3.86, 0.99-15.04, $\mathrm{P}=0.052$ ) were associated with higher mortality but only as a trend (table 2). At multivariate analysis only $\mathrm{FEV}_{1}$ remained independently associated with 
Table 2 Factors associated with exacerbations and all-cause mortality at multivariate analysis

\begin{tabular}{|c|c|c|}
\hline Factor & OR $(95 \% \mathrm{Cl})$ & $P$ values \\
\hline \multicolumn{3}{|l|}{ At least one exacerbation/year } \\
\hline ACT score & 0.87 (0.82 to 0.93$)$ & 0.000 \\
\hline Number of baseline exacerbations* & 1.28 (1.04 to 1.57$)$ & 0.018 \\
\hline \multicolumn{3}{|l|}{ At least three exacerbations/year } \\
\hline ACT score & 0.93 (0.88 to 0.99$)$ & 0.021 \\
\hline Number of baseline exacerbations* & 1.35 (1.11 to 1.66$)$ & 0.005 \\
\hline \multicolumn{3}{|l|}{ All-cause mortality } \\
\hline Recent $\mathrm{FEV}_{1}{ }^{*}$ & $0.30(0.14$ to 0.65$)$ & 0.002 \\
\hline
\end{tabular}

all-cause mortality (HR 0.30, 95\% CI: 0.14 to $0.65, \mathrm{P}=0.002$ ).

\section{DISCUSSION}

Our study has shown that $59.6 \%$ of patients with asthma experience at least one exacerbation in a year, $32.4 \%$ experience at least three exacerbations in a year, and the all-cause mortality rate is $3.7 \%$ (27.3 per 1000 person years). Exacerbations were less likely with better baseline asthma control and more likely with higher number of baseline exacerbations. Mortality was lower with higher recent $\mathrm{FEV}_{1}$.

The rates of exacerbations and mortality observed in this study are much higher than the rates observed in developed settings and higher than the $1 \%$ asthma mortality rate for Uganda reported in the Global Burden of Disease report. ${ }^{4-8}$ For example, De Marco et al reported a mortality incidence rate of only $1.1 / 1000$ person years in a cohort of Italian young adults (20-44 years) followed up for 7 years. $^{7}$ Although the $27.3 / 1000$ person years found in our cohort could be because we reported all-cause mortality while the De Marco study reported asthma-specific mortality, the 27-fold higher mortality rate we observed in this study indicates that asthma mortality rates in Uganda are very high. The associations between exacerbations and mortality with asthma control, number of baseline exacerbations and $\mathrm{FEV}_{1}$ have been previously reported. ${ }^{57}$ Both the ACT and $\mathrm{FEV}_{1}$ are measures of asthma control; ACT uses symptoms, medication use and work impairment to assess asthma control, while $\mathrm{FEV}_{1}$ is an objective measure of the severity of airflow obstruction, a component of asthma control. Therefore, the grim asthma treatment outcomes in this study are most likely a reflection of uncontrolled asthma due to limited access to asthma treatment in our setting. The higher rates may also be race related, since the African race has been found to be associated with more severe asthma. ${ }^{9}$ The lack of use of recommended asthma medications, particularly ICS in this cohort, calls for efforts to increase availability and affordability of asthma medication. Increased access to medicines has been reported to result in better asthma treatment outcomes in some settings, such as the case of Brazil where hospitalisations were significantly reduced with increased access to medications. ${ }^{10}$ In conclusion, the rates of asthma exacerbations and mortality observed in this study are very high and require strengthening of the health systems to improve asthma care in Uganda.

Acknowledgements The authors wish to thank the patients who participated in the study. We specifically thank Mr Rogers Sekibira who managed the data. We thank the study nurses, administrators and the management of Mulago Hospital and Makerere University for facilitating different aspects of the study. Finally, we thank Wide spectrum Uganda for funding the pilot Uganda Registry for Asthma and COPD (URAC) which formed the basis for obtaining the funding from the GSK Trust In Science Africa.

Contributors BJK conceived the idea of the project and wrote the initial proposal. TvdM, MRK and HMB critically advised the writing of the proposal. CdJ and LM supported data analysis. WK and AM performed patients' clinical reviews. All authors critically reviewed and contributed to manuscript writing.

Funding This study was funded by the GSK's Trust In Science Africa Project. Competing interests None declared.

Patient consent Not required.

Ethics approval Mulago Hospital Research and Ethics Committee.

Provenance and peer review Not commissioned; externally peer reviewed.

(c) Article author(s) (or their employer(s) unless otherwise stated in the text of the article) 2018. All rights reserved. No commercial use is permitted unless otherwise expressly granted.

\section{REFERENCES}

12017 GINA Report, Global Strategy for Asthma Management and Prevention. 2017 cited 25 Jun 2017. http://ginasthma.org/2017-gina-report-global-strategy-forasthma-management-and-prevention/

2 Lane S, Molina J, Plusa T. An international observational prospective study to determine the cost of asthma exacerbations (COAX). Respir Med 2006;100:434-50.

3 Dougherty RH, Fahy JV. Acute exacerbations of asthma: epidemiology, biology and the exacerbation-prone phenotype. Clin Exp Allergy 2009:39:193-202.

4 Ebmeier S, Thayabaran D, Braithwaite I, et al. Trends in international asthma mortality: analysis of data from the WHO Mortality Database from 46 countries (1993-2012). The Lancet 2017;390:935-45.

5 Ali Z, Dirks CG, Ulrik CS. Long-term mortality among adults with asthma: a 25-year follow-up of 1,075 outpatients with asthma. Chest 2013;143:1649-55.

6 Schatz M, Meckley LM, Kim M, et al. Asthma Exacerbation Rates in Adults Are Unchanged Over a 5-Year Period Despite High-Intensity Therapy. J Allergy Clin Immunol 2014:2:570-4.

7 de Marco R, Locatelli F, Cazzoletti L, et al. Incidence of asthma and mortality in a cohort of young adults: a 7-year prospective study. Respir Res 2005;6:95.

8 Global Burden of Disease Visualisations: Cause of Death. http://www.thelancet.com/ lancet/visualisations/cause-of-death (cited 14 Dec 2017).

9 Gamble CM. Racial Disparities in Asthma Severity: a Comparison Between Black and White Adult Asthmatics in the Severe Asthma Research Program: University of Pittsburgh, 2011.

10 Comaru T, Pitrez PM, Friedrich FO, et al. Free asthma medications reduces hospital admissions in Brazil (Free asthma drugs reduces hospitalizations in Brazil). Respir Med 2016;121:21-5. 